\title{
Bingöl İlinde Faaliyet Gösteren Bir Meşrubat Firmasının Ulaştırma Modelleri ile Dağıtım Planı Oluşturması *
}

\section{Creating a Distribution Plan With the Transportation Model of a Beverage Firm Operating in Bingol}

\author{
Muhsin Tan \& Sait Patır
}

İşletme Bölümü, Bingöl Üniversitesi, Bingöl, Türkiye

\begin{abstract}
Özet
Günümüzde ticari etkileşimlerin artmasıyla birlikte birçok firmanın pazar payları büyümektedir. Bu durumun sonucu olarak üretim kapasitelerinin artmasına paralel dağıtım kanalları önceki yıllara göre daha kompleks bir hal almaktadır. Bu karışıkığı çözmek için geliştirilen ulaştırma modelleri basit bir şekilde, ürünlerin bir yerden bir yere nakledilmesi faaliyetinin minimum maliyetle gerçekleşebileceğini araştıran bir doğrusal programlama çeşidi olarak tanımlanmaktadır. Bu çalışmada, ulaştırma modelleri ile ilgili çeşitli teorik bilgiler ele alınmış ve Bingöl İlinde faaliyet gösteren bir meşrubat firmasına ait dağıtım problemi ve bu dağıtımın maliyet optimizasyonu için ulaştırma modelinin kullanılabilirliği araştırılmaktadır. Araştırma sonucunda kurulan yeni dağııım planının, meşrubat firmasının kullanmış olduğu mevcut dağıtım planına göre aylık \% 10.86 oranında bir tasarruf sağladığı tespit edilmiştir.

Anahtar kelimeler: Ulaştırma Modeli, Optimizasyon, VAM, MODI

JEL Kodu: M10, R42, C61
\end{abstract}

\section{Abstract}

Today, there is an increasing at the market shares of many companies as a result of changed commercial interactions. As a consequence of this situation, distribution channels become more complex according to the past in parallel with the increase of production capacities. The transportation models developed to solve this confusion are simply defined as a type of linear programming that explores the ability to transfer products from one location to another with minimal cost. In this study, various theoretical information about transportation models is discussed and the availability of transportation model for cost optimization of distribution problem of a soft drink company operating in Bingöl Province is investigated. As a result of the research, it was determined that the new distribution plan saved $10,86 \%$ of monthly transportation cost according to the current distribution plan.

Keywords: Transportation Modeling, Optimization, VAM, MODI

JEL Code: M10, R42, C61

\footnotetext{
* Bu çalışma "Innovation and Gloabal Issues in Social Sciences 2017" (Inglobe) isimli kongrede sözlü bildiri olarak sunulmuştur.

CONTACT : Muhsin Tan, mtan@bingol.edu.tr, ORCID ID: orcid.org/0000-0001-9418-4514; Sait Patır, spatir@bingol.edu.tr, ORCID ID: orcid.org/0000-0002-1592-1094 


\section{Giriş}

Günümüzün artan rekabet ortamında işletmelerin karlılıklarını korumak ve sürdürülebilirliklerini sağlamak için bir dizi kararlar almaları, ürün veya hizmetler için çeşitli iyileştirmeler yapmaları gereklidir. Bununla birlikte arz edilen ürün veya hizmetlerin en kısa sürede ve en iyi kalitede karşılanması iş dünyasının temel prensibidir. Bundan dolayı işletmelerin sektörde bulunan rakipleriyle rekabet edebilmesi için maliyetlerin azaltılması ve en aza indirmesi kaçınılmaz bir zorunluluktur (Patır, 2009: 63). Çünkü işletmelerin küresel rekabet ortamında çeşitli radikal kararlar alıp değişen pazar koşullarına hızlı bir biçimde adapte olmaları, kar edebilmelerini ve varlığını sürdürebilmelerini sağlayacaktır (Çatı \& Baydaş, 2008: 213). Bunların yanında planlamanın çok önemli bir işlev yerine getirdiği modern toplumda, insan ve eşyaların gereken hareketliliğinin sağlanması bakımından ulaştırma faaliyeti çok önemli bir role sahiptir (Özkan, 2012: 18).

İşletmelerin toplam maliyetleri içinde en önemli hesaplamalardan biri olan dağıtım maliyetlerinin minimum düzeye çekilmesi, rekabet ve sürdürülebilirlik açısından önem arz etmektedir. Ulaştırma problemi, teorik ve ekonomik açıdan üzerinde durulan ve çokça çalışmalar yapılan konulardan birisidir (Karaoğlan \& Altıparmak, 2005: 443).

Ulaştırma Modelinin gelişim süreci incelendiğinde model ile ilgili ilk çalışmaların Kantorovich tarafından yapıldığı görülmektedir (Tekin, 2008: 126). Bu çalışmaları F.L. Hitchcook, sistematik bir biçimde geliştirerek 1941 yılında petrol endüstrisinde nakliye ve dağıtım maliyetlerini minimize etmek için uygulamıştır. Takip eden yıllarda, T.C. Koopmans tarafından yapılan çalışmalar neticesinde genişletilen ulaştırma modelini, G.B. Dantzig doğrusal programlama modeli şeklinde formüle etmiştir (Sarıaslan, 1986: 209).

$\mathrm{Bu}$ çalışmalara ek olarak, daha sonraki yıllarda, ulaştırma probleminin çözümü için yeni metotlar geliştirilmiştir. Geliştirilen metotlar ve yapılan bir takım katkılar aşağıdaki tabloda gösterilmiştir (Tekin, 2004: 116).

Tablo 1. Ulaştırma probleminin çözümüne katkıda bulunan bilim insanları ve yaptıkları katkılar

\begin{tabular}{|l|l|}
\hline Bilim İnsanı & Geliştirilen Metot veya Yapılan Katkı \\
\hline T.C. Koopmans & "Ulaştırma Sisteminin Optimum Kullanımı” adlı bir eser \\
\hline G.B. Dantzing ve W.W. Cooper & Kuzeybatı Köşe Yöntemi ve Atlama Taşı Metodu \\
\hline R.O. Ferguson & Basitleştirilmiş Dağıtım Yöntemi (MODİ) \\
\hline W.R. Vogel & $\begin{array}{l}\text { Vogel Yaklaşım Yöntemi - VAM (Vogel's Approximation } \\
\text { Method) }\end{array}$ \\
\hline G.B. Dantzing & $\begin{array}{l}\text { Dejenerayon durumları ve dejenerasyon durumunun ortadan } \\
\text { kaldırılmasına ilişkin çözümlemeler }\end{array}$ \\
\hline Russell & RAM Yöntemi (Russell's Approximation Method) \\
\hline
\end{tabular}

Kaynak: Mahmut Tekin, Saylsal Yöntemler; Bilgisayar Çözümlü Araştırmalar, Konya, 2004, s.116.

$\mathrm{Bu}$ çalışma, işletmelerin dağıtım planlamasında kullanılan ulaştırma modellerinin uygulanışını göstermeyi amaçlamaktadır. Çalışma beş bölümden oluşmaktadır. İlk bölümde ulaştırma modeline dair çeşitli teorik bilgiler verilmiştir. İkinci bölümde, ulaştırma modelinin matematiksel modeli ele alınmış, üçüncü bölümde ise ulaştırma modelinin algoritması ve çözüm aşamaları verilmiştir. Uygulama kısmında, Bingöl İlinde faaliyet gösteren bir meşrubat firmasının dağıtım planlaması için ulaştırma modeli uygulanmak suretiyle yeni bir çözüm 
sunulmuştur. Çalışmanın son bölümünde ise elde edilen sonuçlar ele alınmıştır ve bir takım öneriler sunulmuştur.

\section{Ulaştırma Modeli}

Ulaştırma problemi, yöneylem araştırmasındaki çalışmalarda çokça başvurulan optimizasyon problemlerden biridir (Yang \& Liu, 2007: 879). Ulaştırma modeli, doğrusal programlama modelinin özel bir çeşididir. Bu çeşit modellerin temel amacı, işletmelerin belli bir kapasiteyle üretim yapmakta olan üretim merkezlerinden (fabrika), belli bir miktarda talebi olan tüketim merkezlerine (satış bölgesi) yollayacağı ürünlerin toplam ulaştırma maliyetini minimum seviyeye çekecek bir biçimde ulaştırılmasını sağlamaktır (Esin, 1988: 214).

Ulaştırma Modelinde üretim merkezlerinin (fabrika) mevcut sahip olduğu üretim kapasitesiyle beraber tüketim merkezlerinden (satış bölgesi) gelen talepler göz önüne alınarak dağıtım gerçekleştirilmektedir. Ulaştırma Modeli her zaman en düşük maliyeti içeren bir taşıma planını gerçekleştiremeyebilir. Bu model, hali hazırda işletmenin elinde olan kaynak ve imkânlara göre arz ve talep göz önüne alınarak minimum (en az) maliyetin elde edileceği taşıma işleminin yapılmasını amaçlamaktadır (Tekin, 2008: 126).

Ulaştırma modelinin doğrusal programlama modelinin özel bir türü olmasından dolayı doğrusal programlama modeli için kabul edilen ve uygulanan kural ve prosedürlerin hepsi ulaştırma modeli için de geçerlidir. İşletmelerin herhangi bir probleminin ulaştırma modeli vasıtasıyla çözülebilmesi için uyulması gereken başka varsayımlar da bulunmaktadır. Bir soruna konu olan mal ve hizmetlerin aynı birimlerle ifade edilmeleri gerekmektedir. Bu gerekliliğe homojenlik koşulu denir (Ertuğrul vd., 2008: 4).

Doğrusal programlama modeli için kabul edilen aşağıdaki bazı varsayımlar ulaştırma modeli için de geçerlidir (Görkey, 2009: 5):

1. Doğrusal programlama modelindeki değişkenlerin değeri ya sıfır ya da sıfırdan büyük yani daima pozitiftir.

2. Doğrusal programlama modelini oluşturan katsayı ve parametrelerin bilindiği ve ilgili dönem süresince değişmediği, sabit kaldığı kabul edilmektedir. Modelin ilgili parametrelere ne kadar duyarlı olduğu duyarlılık analizleriyle belirlenebilmektedir.

3. Doğrusal programlama modelini meydana getiren değişkenler arasında toplanabilme özelliği vardır.

4. Tüm doğrusal programlama modelinde, modeldeki tüm fonksiyonların doğrusal olması zorunludur.

Ulaştırma Modeli arz ve talep edilen ürünlerin miktarlarının sabit olduğunu kabul etmektedir. Ulaştırma Modelinde kabul edilebilir bir çözümün ortaya çıkması için arz ve talep miktarlarının toplamının eşit olması gerekmektedir. Belli bir kaynaktan belli bir merkeze ulaştırılacak olan ürünlerin maliyeti ürün miktarıyla ilişkili olduğundan taşıma işlemi sonucunda ortaya çıkan toplam taşıma maliyeti, taşıma işleminin yapıldığı güzergâhtaki ürün miktarıyla ürün taşıma maliyetinin çarpımıyla hesaplanmaktadır. Her hangi bir Ulaştırma Modeli probleminin çözümü için aşağıdaki bilgilere gereksinim duyulmaktadır (Düzakın, 2005: 47-48):

- Birim taşıma maliyeti

- Talep miktarı

- Arz miktarı 


\section{Ulaştırma Modelinin Matematiksel Modeli}

Ulaştırma modeli, bir ürünün bir veya birkaç sunum merkezinden bir veya birkaç istem merkezine minimum maliyet ile dağıtılmasını planlamaya yarayan matematiksel bir modeldir. $\mathrm{m}$ adet sunum merkezinde $\mathrm{n}$ adet istem merkezine ulaştırılmaya çalış1lan bir ulaştırma probleminde, $\mathrm{j}$. istem merkezi $b_{j}$ miktarında ürün isterken i. sunum merkezi de ancak $a_{i}$ miktarında ürün sunabilmektedir. i. arz merkezinden j. istem merkezine bir birim malın ulaştırılma maliyeti $c_{i j}$ kadardır (Ertuğrul vd., 2008: 4).

Doğrusal programlama problemi olarak ifade edilen ulaştırma probleminin matematiksel modeli aşağıda verilmiştir (Hallaç, 1978: 418):

Amaç Fonksiyonu:

Minimum $\mathrm{Z}=c_{11} X_{11}+c_{12} X_{12}+\cdots+c_{1, n-1} X_{1, n-1}+c_{1 n} X_{1 n}+c_{21} X_{21}+c_{22} X_{22}+\cdots+$

$c_{2, n-1} X_{2, n-1}+c_{2 n} X_{2 n}+\cdots+c_{m-1} X_{m-1}+c_{m-1,2} X_{m-1,2}+\cdots+c_{m-1, n-1} X_{m-1, n-1}$

$+c_{m-1, n} X_{m-1, n}+c_{m 1} X_{m 1}+c_{m 2} X_{m 2}+\cdots+c_{m, n-1} X_{m, n-1}+c_{m, n} X_{m, n}$

Kisitlayıcilar:

$$
\begin{gathered}
X_{11}+X_{12}+\cdots X_{1 n} \leq a_{1} \\
X_{21}+X_{22}+\cdots X_{2 n} \leq a_{2} \\
\cdots \\
X_{m-1,1}+X_{m-1,2}+\cdots X_{m-1, n} \leq a_{m-1} \\
X_{m 1}+X_{m 2}+\cdots X_{m n} \leq a_{m} \\
X_{11}+X_{21}+\cdots X_{m 1} \geq b_{2} \\
X_{12}+X_{22}+\cdots X_{m 2} \geq b_{2} \\
\cdots \\
X_{1, n-1}+X_{2, n-1}+\cdots X_{m, n-1} \geq b_{m-1} \\
X_{1 n}+X_{2 n}+\cdots X_{m n} \geq b_{n}
\end{gathered}
$$

Pozitiflik koşulu:

$$
X_{i j} \geq 0(i=1,2,3, \ldots, m ; j=1,2,3, \ldots, n)
$$

$\mathrm{i}=1,2, \ldots, \mathrm{n}$ olmak üzere $\mathrm{n}$ kaynağa (fabrika) ve $\mathrm{j}=1,2, \ldots, \mathrm{m}$ olmak üzere $\mathrm{m}$ tüketim bölgesine (pazara) sahip olduğumuzu varsayalım. i. kaynaktan j. tüketim bölgesine taşıma maliyeti ünite başına $c_{i j}$ ve taşınılan ünite miktarını $x_{i j}$ ile gösterilerek toplam maliyet

(amaç fonksiyonu)

$Z_{\text {min }}=n_{i=1} \quad m_{j=1} x_{i j} c_{i j}$

olur. i. fabrikanın üretim miktarı $a_{i j}$ ve i. tüketim bölgesinin talep miktarı $b_{j}$ ile gösterilerek toplam üretimin toplam talebe eşitlik varsayımı

$n_{i=1} a_{i}=m_{j=1} b_{j}$

olur. i. fabrikadan i. pazara negatif bir miktarın taşınması söz konusu olamaz ve 
$X_{i j} \geq 0(i=1, \ldots, n ; j=1, \ldots, m)$

pozitiflik şartı yazılır. Herhangi bir fabrikadan bütün tüketim bölgelerine gönderilen mallar toplamı o fabrikada yapılan üretim miktarına eşit olma şartı

$m_{i=1} x_{i j}=a_{i} \ldots(i=1, \ldots, n)$

bağıntısı ile ve herhangi bir pazara bütün fabrikalardan gelen mallar toplamının o tüketim bölgesinin talebine eşit olması şartı

$n_{j=1} x_{i j}=p_{j} \ldots(j=1, \ldots, m)$

bağıntısı ile matematiksel bir biçimde yazılır. (1), (2), (3), (4), (5) bağıntıları ile belirlenen dağıtım problemlerine ulaştırma modeli adı verilmektedir.

Problemin uygun bir çözümünün olduğu düşünülürse; toplam istem toplam sunumdan fazla olamaz. Uygun çözümdeki karar değişkenleri $\left(x_{i j}\right)$ tam sayı değerinde olmadığında elde edilen çözümün kullanışlı olmadığı anlaşılır. Problemin minimum bir optimum çözümünün olduğunu ifade edebilmek için sunum $\left(a_{i}\right)$, istem $\left(b_{j}\right)$ ve karar değişkenleri $\left(x_{i j}\right)$ tam sayı değerinde veya 0 olmak zorundadır. Genel olarak bu tür problemlerde, üretim merkezlerinin tümünde üretilen ürünlerin toplam sunumunun, tüketim merkezlerinin toplam istemine eşit olduğu kabul edilir. $\mathrm{Bu}$ şart sağlandığında problem dengeli ulaştırma problemidir ve aşağıdaki gibi gösterilir (Ertuğrul vd., 2008: 5).

$$
\begin{aligned}
& \sum_{j=1}^{n} b_{j}=\sum_{j=1}^{n}\left(\sum_{i=1}^{m} x_{i j}\right) \\
& \sum_{i=1}^{m}\left(\sum_{j=1}^{n} x_{i j}\right)=\sum_{i=1}^{m} a_{i}
\end{aligned}
$$

Bazen ulaştırma problemlerinde bu eşitlik sağlanmayabilir, yanı arz edilen sunum miktarı istem miktarından az veya daha fazla olabilir. Bu tur durumlarda, problemin dengelenmesi için probleme kukla (dummy) üretim veya tüketim merkezi eklenir (Özkan, 2012: 26).

\section{Ulaştırma Algoritması}

Ulaştırma problemde çözüm mantığı, simpleks yöntemine paralellik göstermektedir. Çözüm için oluşturulan tablonun farklı olması sebebiyle her ne kadar bu paralellik çok açık olmasa da aslında ulaştırma modelinin iterasyon aşamaları, simpleks yönteminin iterasyon aşamalarının basitleştirilmiş halidir. Bu basitlik ise ulaştırma modelinin özel yapısından ortaya çıkmaktadır. Simpleks yöntemindeki gibi, ulaştırma problemlerinde de temel uygun çözümlere karşılık gelen köşe noktaları araştırılmakta ve optimal çözüm bulununcaya kadar köşe noktalarında gezinti yapılmaktadır (Görkey, 2009: 12).

Ulaştırma modelinde istem ve sunum kısıtlarını sağlayan herhangi bir $X=X_{11}, X_{12} \ldots X_{n m}(i=1,2,3, \ldots, m ; j=1,2,3, \ldots, n)$ vektörüne çözüm denilmektedir. Bununla birlikte, istem ve sunum kısıtları ile birlikte pozitiflik koşulunu da sağlayan çözümlere, kabul edilebilir çözüm denilmektedir. Kabul edilebilir çözümde bulunan temel değişken (değer alan karar değişkeni) sayısı (m+n-1)'e eşit olduğunda “temel kabul edilebilir” bir çözüm bulunmuş 
olmaktadır. Problemin en iyi çözümü ise, temel kabul edilebilir çözümler arasında amaç fonksiyonunu en iyi belirleyen çözümdür (Doğan, 2005: 83).

Ulaştırma modeli problemlerinde çözüm metodu dört temel basamaktan oluşmaktadır. $\mathrm{Bu}$ dört temel basamak aşağıda verilmiştir (Tekin, 2004: 120):

1. Basamak: Taşıma maliyetlerini gösteren ulaştırma tablosunun başlangıç tablosu olarak kurulmas1,

2. Basamak: Başlangıç temel uygun çözümünün araştırılması,

3. Basamak: Bulunan temel uygun çözümünün en uygun çözüm olup olmadığının test edilmesi,

4. Basamak: 2. Basamak'a dönüş yapılarak, 2. Basamak ile 4. Basamak arasındaki işlemlerin optimal (en uygun) çözüm sağlanana kadar tekrar araştırılması.

Ulaştırma Modellerinde başlangıç temel uygun çözümünün araştırılması için kullanılan metotlar; Kuzey-Batı Köşesi Metodu, En Düşük Maliyetli Gözeler (hücre) Metodu ve Vogel (VAM) Başlangıç Yöntemi olmak üzere üç metot bulunmaktadır (Tekin, Sayısal Yöntemler, 2008: 131).

\subsection{Kuzey-Batı Köşesi Metodu}

Ulaştırma problemlerine sistematik bir çözüm aramak için ilk olarak George B. Dantzig tarafından ortaya atılan bu yöntem, A. Charnes ve W. W. Cooper tarafindan 1953 yılında geliştirilmiştir. Sonraki yıllarda R. Schlaifer ve A. Henderson tarafından getirilen bazı değişiklikler sonucunda yöntem bugünkü halini almıştır. Kuzey batı köşesi yöntemi, çözümün bulunması için başlangıç tablosunun kuzey batı köşesinden başlanılarak gereken miktarların dağıtılması sebebiyle bu adı almıştır.

Kuzey batı köşesi yönteminde, ulaştırma tablosunun sol üst hücresinden $\left(x_{11}\right)$ başlanıp birinci fabrikada (üretim yeri) elverişli mallar mümkün olduğunca dağıtılır. Yani $x_{11}$ gözesine yapılacak olan dağıtım miktarının sıra şartı $a_{1}$ ve sütun şartı $b_{1}$ den hangisi küçükse, o miktar kadar yapılır. Eğer $b_{1}<a_{1}$ ise birinci tüketim merkezinin (istem merkezi) istemi doyurulduktan sonra geriye kalan sunum miktarı $x_{12}$ olarak şekilde dağıtımı yapılır. Eğer $b_{1}>a_{1}$ ise ilk sunum merkezindeki tüm mallar birinci istem merkezine dağıtılır. Geriye kalan ve doyurulmayan istem miktarı ise ikinci sunum miktarından karşılanarak $x_{21}$ olarak dağıtım gerçekleştirilir. Böylelikle her seferinde bir sağ taraftaki gözeye veya bir aşağıda bulunan gözeye geçilip her sıra (sunum) ve sütun (istem) şartını sağlayacak şekilde gerekli tüm dağıtımlar yapılır (Öztürk, 2004: 343).

Kuzey-batı kösesi yönteminin rahat bir şekilde uygulanabilen bir yöntem olmasına rağmen bir takım dezavantajları bulunmaktadır. Bu yöntemde dağıtım planlamasında sadece arz ve talep miktarları göz önünde bulundurulmasına rağmen birim taşıma maliyetleri önemsenmemektedir. $\mathrm{Bu}$ sebeple ulaşılan çözüm çoğunlukla optimal (en iyi) çözümden çok uzak bir değer vermektedir (Görkey, 2009: 19).

\subsection{En Düşük Maliyetli Gözeler (Hücre) Metodu}

Ulaştırma problemlerinin bir başka çözüm metodu olan En Düşük Maliyetli Gözeler Metodu genellikle küçük boyutlu ulaştırma problemlerinin çözümünde hız avantajına sahip 
olduğu için çok tercih edilmektedir. Bu yöntemin uygulanmasında üç farklı yaklaşım söz konusudur (Serper \& Gürsakal, 1982: 85-89);

1. Sıra yaklaşımı: Başlangıç tablosunda bulunan birinci sıradaki en küçük birim maliyetli hücreden başlanarak ilk sıranın gerekleri karşılanıncaya kadar dağıtım yapılır. Bu işlem sırasıyla diğer sıralar için de yapılır.

2. Sütun yaklaşımı: Başlangıç tablosunda bulunan birinci sütundaki en küçük maliyetli hücreye ilk sıranın gerekleri karşılanıncaya dağıtım yapılır. Son sütunun gerekleri karşılanana kadar bu işleme devam edilir.

3. Genel yaklaşım: Bu metotta sıra veya sütun farkı göz önüne alınmadan başlangıç tablosunda bulunan bütün birim maliyetleri arasındaki en küçük hücreden başlanarak dağıtımlar yapılır. Bu dağıtımlarda sıra ve sütun kısıtlayıcılarına uyulmaktadır.

\subsection{Vogel (VAM) Başlangı̧̣ Yöntemi}

William R. Vogel tarafindan 1958 yılında geliştirilen yöntem, başlangıç çözüm yöntemleri içinde optimum çözüme en yakın sonucu veren metot olma özelliğini taşımaktadır. Optimum sonuca ulaşmada bu metot zaman tasarrufu sağlamaktadır.

VAM yönteminin çözüm aşamaları aşağıdaki gibidir (Timor, 2001: 128);

1. Her bir satır ve sütunda bulunan en düşük iki maliyet bulunarak farkları alınır. Bulunan değer ceza (fırsat) maliyeti biçiminde adlandırılır ve en iyi rotanın izlenmesi sebebiyle üstlenilecek maliyet anlamına gelmektedir.

2. En yüksek ceza (fırsat) maliyetinin olduğu sahip satır ya da sütun belirlenir.

3. En yüksek ceza (fırsat) maliyetinin olduğu satır veya sütundaki en düşük maliyetli gözeye, arz ve talep miktarları göz önüne alınacak şekilde, mümkün olabilecek en yüksek miktarda dağıtım yapılır.

4. Arz miktarının tamamı dağıtılan satır veya talebi karşılanan sütun tablodan elenir.

5. Söz konusu satır veya sütunun elendiği yeni matris, indirgenmiş matris olarak ifade edilmektedir. Bu matriste maliyet farkları tekrar hesaplanır.

6. İkinci aşamaya dönülerek, elenmemiş tek satır ya da tek sütun kalıncaya kadar işlemler tekrar eder ve başlangıç temel uygun çözüm bu metotla bulunur.

\section{Uygulama}

Çalışmanın bu bölümünde Bingöl İlinde faaliyet gösteren bir meşrubat firmasının ürünlerini işletmenin depolarından tüketim merkezlerine ulaştırmasında üstlendiği dağıtım maliyetinin minimum düzeyde gerçekleştirebilmesini sağlamak için ulaştırma modeli yardımıyla yeni bir çözüm sunulmuştur.

$\mathrm{Bu}$ çalışmanın amacı, meşrubat firmasından elde edilen bilgiler doğrultusunda kurulan ulaştırma modeli yardımıyla aylık dağıtım maliyetini minimum seviyeye indirgemektir. Kurulan model neticesinde meşrubat firmasının mevcut dağıtım planına kıyasla toplam aylık ulaştırma maliyetinde bir düşüş olup olmayacağının test edileceği yeni bir dağıtım planı oluşturulmuştur. Meşrubat firmasının dağıtım yaptığı yerler ile depoları arasındaki birim taşıma maliyetleri ve dağıtım miktarları Tablo 2'de gösterilmiştir. 
Tablo 2. Meşrubat firmasının dağıtım yaptığı yerler ile tüketim merkezleri arasındaki birim taşıma maliyetleri ve dağıtım miktarları

\begin{tabular}{|c|c|c|c|c|c|c|c|c|c|}
\hline $\begin{array}{l}\text { Marketler } \\
\text { Depolar }\end{array}$ & $\begin{array}{l}\text { Bingöl } \\
\text { Merkez } \\
\text { (D1) }\end{array}$ & $\begin{array}{l}\text { Genç } \\
\text { (D2) }\end{array}$ & $\begin{array}{l}\text { Karliov } \\
\text { a } \\
\text { (D3) }\end{array}$ & $\begin{array}{l}\text { Solhan } \\
\text { (D4) }\end{array}$ & $\begin{array}{l}\text { Kı ̆̆ı } \\
\text { (D5) }\end{array}$ & $\begin{array}{l}\text { Adaklı } \\
\text { (D6) }\end{array}$ & $\begin{array}{l}\text { Yedisu } \\
\text { (D7) }\end{array}$ & $\begin{array}{l}\text { Yayladere } \\
\text { (D8) }\end{array}$ & Sunum \\
\hline $\begin{array}{l}\text { Bingöl } \\
\text { Merkez } \\
\text { (S1) }\end{array}$ & $\begin{array}{l}0,008 \\
\text { TL } \\
98850\end{array}$ & $\begin{array}{l}0,06 \mathrm{TL} \\
X_{12}\end{array}$ & $\begin{array}{l}0,18 \mathrm{TL} \\
X_{13}\end{array}$ & $\begin{array}{l}0,14 \mathrm{TL} \\
18890\end{array}$ & $\begin{array}{l}0,19 \\
\text { TL } \\
3500\end{array}$ & $\begin{array}{l}0,20 \mathrm{TL} \\
250\end{array}$ & $\begin{array}{l}0,32 \mathrm{TL} \\
X_{17}\end{array}$ & $\begin{array}{l}0,25 \mathrm{TL} \\
1110\end{array}$ & 122600 \\
\hline $\begin{array}{l}\text { Genç } \\
\text { (S2) }\end{array}$ & $\begin{array}{l}0,06 \mathrm{TL} \\
X_{21}\end{array}$ & $\begin{array}{l}0,007 \\
\text { TL } \\
21150\end{array}$ & $\begin{array}{l}0,24 \mathrm{TL} \\
X_{23}\end{array}$ & $\begin{array}{l}0,19 \mathrm{TL} \\
X_{24}\end{array}$ & $\begin{array}{l}0,25 \\
\mathrm{TL} \\
X_{25}\end{array}$ & $\begin{array}{l}0,26 \mathrm{TL} \\
X_{26}\end{array}$ & $\begin{array}{l}0,36 \mathrm{TL} \\
1950\end{array}$ & $\begin{array}{l}0,29 \mathrm{TL} \\
X_{28}\end{array}$ & 23100 \\
\hline $\begin{array}{l}\text { Karlıova } \\
\text { (S3) }\end{array}$ & $\begin{array}{l}0,18 \mathrm{TL} \\
X_{31}\end{array}$ & $\begin{array}{l}0,24 \mathrm{TL} \\
X_{32}\end{array}$ & $\begin{array}{l}0,007 \\
\text { TL } \\
8090\end{array}$ & $\begin{array}{l}0,26 \mathrm{TL} \\
X_{34}\end{array}$ & $\begin{array}{l}0,35 \\
\text { TL } \\
X_{35} \\
\end{array}$ & $\begin{array}{l}0,36 \mathrm{TL} \\
2950\end{array}$ & $\begin{array}{l}0,14 \mathrm{TL} \\
X_{37}\end{array}$ & $\begin{array}{l}0,42 \mathrm{TL} \\
X_{38}\end{array}$ & 11040 \\
\hline İstem & 98850 & 21150 & 8090 & 18890 & 3500 & 3200 & 1950 & 1110 & $\begin{array}{l}156740 \\
156740\end{array}$ \\
\hline
\end{tabular}

Yukarıdaki problemin uygun bir şekilde çözülebilmesi için toplam istemin toplam sunumdan küçük veya eşit olması gerekmektedir. Bu problemde, $\sum_{i=1}^{3} a_{i} \geq \sum_{j=1}^{8} b_{i}$ şartı sağlandığı için uygun çözüm vardır. Problemin denklemi ve kısıtlayıcıları aşağıdaki gibidir.

Minimum $\mathrm{Z}=0,008 X_{11}+0,06 X_{12}+0,18 X_{13}+0,14 X_{14}+0,19 X_{15}+0,20 X_{16}+$ $0,32 X_{17}+0,25 X_{18}+0,06 X_{21}+0,007 X_{22}+0,24 X_{23}+0,19 X_{24}+0,25 X_{25}+$ $0,26 X_{26}+0,36 X_{27}+0,29 X_{28}+0,18 X_{31}+0,24 X_{32}+0,007 X_{33}+0,26 X_{34}+0,35 X_{35}$ $+0,36 X_{36}+0,14 X_{37}+0,42 X_{38}$

Kisitlayicilar:

$$
\begin{aligned}
& X_{11}+X_{12}+X_{13}+X_{14}+X_{15}+X_{16}+X_{17}+X_{18} \leq 122600 \\
& X_{21}+X_{22}+X_{23}+X_{24}+X_{25}+X_{26}+X_{27}+X_{28} \leq 23100 \\
& X_{31}+X_{32}+X_{33}+X_{34}+X_{35}+X_{36}+X_{37}+X_{38} \leq 11040 \\
& X_{11}+X_{21}+X_{31} \geq 98850 \\
& X_{12}+X_{22}+X_{32} \geq 21150 \\
& X_{13}+X_{23}+X_{33} \geq 8090 \\
& X_{14}+X_{24}+X_{34} \geq 18890 \\
& X_{15}+X_{25}++X_{35} \geq 3500 \\
& X_{16}+X_{26}+X_{36} \geq 3200 \\
& X_{17}+X_{27}+X_{37} \geq 1950 \\
& X_{18}+X_{28}+X_{38} \geq 1110 \\
& X_{i j} \geq 0(\mathrm{i}=1,2,3 ; \mathrm{j}=1,2,3,4,5,6,7,8)
\end{aligned}
$$


TOPLAM MALIYET $=0,008 * 98850+0,06 * 0+0,18 * 0+0,14 * 18890+0,19 *$ $3500+0,20 * 250+0,32 * 0+0,25 * 1110+0,06 * 0+0,007 * 21150+0,24 * 0+$ $0,19 * 0+0,25 * 0+0,26 * 0+0,36 * 1950+0,29 * 0+0,18 * 0+0,24 * 0+0,007 *$ $8090+0,26 * 0+0,35 * 0+0,36 * 2950+0,14 * 0+0,42 * 0$

\section{TOPLAM MALIYET $=6396.58 \mathrm{TL}$}

Verilen bu işlemler takip edilerek toplam dağıtım maliyeti hesaplandığında, meşrubat firmasının mevcut dağıtımı için 6396.58 TL'lik bir maliyetin söz konusu olduğu görülmektedir.

Söz konusu maliyetin ne kadar düşürülebileceğini araştırmak için ulaştırma modellerinden faydalanmak gerekmektedir. Problemin çözümüne dair Vogel (VAM) Başlangı̨ç Yöntemi ile elde edilmiş başlangıç tablosu aşağıda verilmiştir.

Tablo 3. Vogel (VAM) Başlangıç Yöntemi ile elde edilmiş başlangıç tablosu

\begin{tabular}{|c|c|c|c|c|c|c|c|c|c|c|}
\hline & & $\begin{array}{l}\text { V1 } \\
0,008\end{array}$ & $\begin{array}{l}\text { V2 } \\
-0,045\end{array}$ & $\begin{array}{l}\text { V3 } \\
-0,165\end{array}$ & $\begin{array}{l}\text { V4 } \\
0,14\end{array}$ & $\begin{array}{l}\text { V5 } \\
0,19\end{array}$ & $\begin{array}{l}\text { V6 } \\
0,20\end{array}$ & $\begin{array}{l}\text { V7 } \\
-0,032\end{array}$ & $\begin{array}{l}\mathrm{V} 8 \\
0,25\end{array}$ & \\
\hline & & (D1) & (D2) & (D3) & (D4) & (D5) & (D6) & D7) & (D8) & Sunum \\
\hline $\begin{array}{l}\text { U1 } \\
0\end{array}$ & (S1) & $\begin{array}{l}0,008 \mathrm{TL} \\
95900\end{array}$ & $\begin{array}{l}0,06 \mathrm{TL} \\
X_{12}\end{array}$ & $\begin{array}{l}0,18 \mathrm{TL} \\
X_{13}\end{array}$ & $\begin{array}{l}0,14 \mathrm{TL} \\
18890\end{array}$ & $\begin{array}{l}0,19 \mathrm{TL} \\
3500\end{array}$ & $\begin{array}{l}0,20 \mathrm{TL} \\
3200\end{array}$ & $\begin{array}{l}0,32 \mathrm{TL} \\
X_{17}\end{array}$ & $\begin{array}{l}0,25 \mathrm{TL} \\
1110\end{array}$ & 122600 \\
\hline $\begin{array}{l}\mathrm{U} 2 \\
0,052\end{array}$ & (S2) & $\begin{array}{l}0,06 \mathrm{TL} \\
1950\end{array}$ & $\begin{array}{l}0,007 \mathrm{TL} \\
21150\end{array}$ & $\begin{array}{l}0,24 \mathrm{TL} \\
X_{23}\end{array}$ & $\begin{array}{l}0,19 \mathrm{TL} \\
X_{24}\end{array}$ & $\begin{array}{l}0,25 \mathrm{TL} \\
X_{25}\end{array}$ & $\begin{array}{l}0,26 \mathrm{TL} \\
X_{26}\end{array}$ & $\begin{array}{l}0,36 \mathrm{TL} \\
X_{27}\end{array}$ & $\begin{array}{l}0,29 \mathrm{TL} \\
X_{28}\end{array}$ & 23100 \\
\hline $\begin{array}{l}\text { U3 } \\
0,172 \\
\end{array}$ & $(\mathbf{S 3})$ & $\begin{array}{l}0,18 \mathrm{TL} \\
1000\end{array}$ & $\begin{array}{l}0,24 \mathrm{TL} \\
X_{32}\end{array}$ & $\begin{array}{l}0,007 \mathrm{TL} \\
8090\end{array}$ & $\begin{array}{l}0,26 \mathrm{TL} \\
X_{34}\end{array}$ & $\begin{array}{l}0,35 \mathrm{TL} \\
X_{35}\end{array}$ & $\begin{array}{l}0,36 \mathrm{TL} \\
X_{36}\end{array}$ & $\begin{array}{l}0,14 \mathrm{TL} \\
1950 \\
\end{array}$ & $\begin{array}{l}0,42 \mathrm{TL} \\
X_{38}\end{array}$ & 11040 \\
\hline & İstem & 98850 & 21150 & 8090 & 18890 & 3500 & 3200 & 1950 & 1110 & $\begin{array}{l}156740 \\
156740\end{array}$ \\
\hline
\end{tabular}

TOPLAM MALIYET $=5768.98 \mathrm{TL}$

Vogel (VAM) Başlangıç Yöntemi ile elde edilmiş başlangıç tablosundaki toplam maliyet 5768.98 TL olarak hesaplanmıştır. Bu aşamadan sonra problemin en uygun çözümünün araştırılması için MODI Optimal Çözüm Yaklaşımıyla optimallik testi yapılacaktır.

$\mathrm{C} 34=0,312-0,26=0,052$

Yol Haritas1: C34=C14-C11+C34-C34

$=18890-95900+1000-0=17890-96900+0-1000$

TASARRUF $=0,052 * 1000=52 \mathrm{TL}$

TOPLAM MALIYET $=5768.98-52=5716.98 \mathrm{TL}$

Yapılan optimallik testinden sonra oluşturulan yeni dağıtım planı Tablo 4'te gösterilmiştir. 
Tablo 4. MODI Optimal Çözüm Yaklaşımı (1. Aşamanın sonu)

\begin{tabular}{|c|c|c|c|c|c|c|c|c|c|c|}
\hline & & $\begin{array}{l}\text { V1 } \\
0,008 \\
\end{array}$ & $\begin{array}{l}\mathrm{V} 2 \\
-0,045 \\
\end{array}$ & $\begin{array}{l}\text { V3 } \\
-0,113 \\
\end{array}$ & $\begin{array}{l}\mathrm{V} 4 \\
0,14 \\
\end{array}$ & $\begin{array}{l}\text { V5 } \\
0,19 \\
\end{array}$ & $\begin{array}{l}\text { V6 } \\
0,20 \\
\end{array}$ & $\begin{array}{l}\text { V7 } \\
0,02 \\
\end{array}$ & $\begin{array}{l}\text { V8 } \\
0,25 \\
\end{array}$ & \\
\hline & & (D1) & (D2) & (D3) & (D4) & (D5) & (D6) & D7) & (D8) & Sunum \\
\hline $\begin{array}{l}\mathrm{U} 1 \\
0\end{array}$ & (S1) & $\begin{array}{l}0,008 \mathrm{TL} \\
96900\end{array}$ & $\begin{array}{l}0,06 \mathrm{TL} \\
X_{12}\end{array}$ & $\begin{array}{l}0,18 \mathrm{TL} \\
X_{13}\end{array}$ & $\begin{array}{l}0,14 \mathrm{TL} \\
17890\end{array}$ & $\begin{array}{l}0,19 \mathrm{TL} \\
3500\end{array}$ & $\begin{array}{l}0,20 \mathrm{TL} \\
3200\end{array}$ & $\begin{array}{l}0,32 \mathrm{TL} \\
X_{17}\end{array}$ & $\begin{array}{l}0,25 \mathrm{TL} \\
1110\end{array}$ & 122600 \\
\hline $\begin{array}{l}\mathrm{U} 2 \\
0,052\end{array}$ & (S2) & $\begin{array}{l}0,06 \mathrm{TL} \\
1950\end{array}$ & $\begin{array}{l}0,007 \mathrm{TL} \\
21150\end{array}$ & $\begin{array}{l}0,24 \mathrm{TL} \\
X_{23}\end{array}$ & $\begin{array}{l}0,19 \mathrm{TL} \\
X_{24}\end{array}$ & $\begin{array}{l}0,25 \mathrm{TL} \\
X_{25}\end{array}$ & $\begin{array}{l}0,26 \mathrm{TL} \\
X_{26}\end{array}$ & $\begin{array}{l}0,36 \mathrm{TL} \\
X_{27}\end{array}$ & $\begin{array}{l}0,29 \mathrm{TL} \\
X_{28}\end{array}$ & 23100 \\
\hline $\begin{array}{l}\mathrm{U} 3 \\
0,12\end{array}$ & (S3) & $\begin{array}{l}0,18 \mathrm{TL} \\
X_{31}\end{array}$ & $\begin{array}{l}0,24 \mathrm{TL} \\
X_{32}\end{array}$ & $\begin{array}{l}0,007 \mathrm{TL} \\
8090\end{array}$ & $\begin{array}{l}0,26 \mathrm{TL} \\
1000\end{array}$ & $\begin{array}{l}0,35 \mathrm{TL} \\
X_{35}\end{array}$ & $\begin{array}{l}0,36 \mathrm{TL} \\
X_{36}\end{array}$ & $\begin{array}{l}0,14 \mathrm{TL} \\
1950\end{array}$ & $\begin{array}{l}0,42 \mathrm{TL} \\
X_{38}\end{array}$ & 11040 \\
\hline & İstem & 98850 & 21150 & 8090 & 18890 & 3500 & 3200 & 1950 & 1110 & $\begin{array}{l}156740 \\
156740 \\
\end{array}$ \\
\hline
\end{tabular}

TOPLAM MALIYET $=5716.98 \mathrm{TL}$

Optimallik testinden sonra yapılan dağıtımların neticesinde toplam maliyet $5716.98 \mathrm{TL}$ olarak bulunmuştur.

$\mathrm{C} 28=0,302-0,29=0,012$

Yol Haritas1: $\mathrm{C} 28=\mathrm{C} 15-\mathrm{C} 11+\mathrm{C} 21-\mathrm{C} 28$

$=1110-96900+1950-0=0-98010+840-1110$

TOPLAM MALIYET $=5716.98 \mathrm{TL}$

Tablo 4'teki dağıtım planının optimallik testinin yapıldığı yeni dağıtım planı aşağıdaki verilen Tablo 5'te gösterilmiştir.

Tablo 5. MODI Optimal Çözüm Yaklaşımı (2. Așamanın sonu)

\begin{tabular}{|c|c|c|c|c|c|c|c|c|c|c|}
\hline & & $\begin{array}{l}\text { V1 } \\
0,008\end{array}$ & $\begin{array}{l}\mathrm{V} 2 \\
-0,045\end{array}$ & $\begin{array}{l}\text { V3 } \\
-0,113\end{array}$ & $\begin{array}{l}\mathrm{V} 4 \\
0,14\end{array}$ & $\begin{array}{l}\text { V5 } \\
0,19\end{array}$ & $\begin{array}{l}\text { V6 } \\
0,20\end{array}$ & $\begin{array}{l}\text { V7 } \\
0,02\end{array}$ & $\begin{array}{l}\text { V8 } \\
0,238\end{array}$ & \\
\hline & & (D1) & (D2) & (D3) & (D4) & (D5) & (D6) & D7) & (D8) & Sunum \\
\hline $\begin{array}{l}\mathrm{U} 1 \\
0\end{array}$ & (S1) & $\begin{array}{l}0,008 \mathrm{TL} \\
98010\end{array}$ & $\begin{array}{l}0,06 \mathrm{TL} \\
X_{12}\end{array}$ & $\begin{array}{l}0,18 \mathrm{TL} \\
X_{13}\end{array}$ & $\begin{array}{l}0,14 \mathrm{TL} \\
17890\end{array}$ & $\begin{array}{l}0,19 \mathrm{TL} \\
3500\end{array}$ & $\begin{array}{l}0,20 \mathrm{TL} \\
3200\end{array}$ & $\begin{array}{l}0,32 \mathrm{TL} \\
X_{17}\end{array}$ & $\begin{array}{l}0,25 \mathrm{TL} \\
X_{18}\end{array}$ & 122600 \\
\hline $\begin{array}{l}\mathrm{U} 2 \\
0,052\end{array}$ & (S2) & $\begin{array}{l}0,06 \mathrm{TL} \\
840\end{array}$ & $\begin{array}{l}0,007 \mathrm{TL} \\
21150\end{array}$ & $\begin{array}{l}0,24 \mathrm{TL} \\
X_{23}\end{array}$ & $\begin{array}{l}0,19 \mathrm{TL} \\
X_{24}\end{array}$ & $\begin{array}{l}0,25 \mathrm{TL} \\
X_{25}\end{array}$ & $\begin{array}{l}0,26 \mathrm{TL} \\
X_{26}\end{array}$ & $\begin{array}{l}0,36 \mathrm{TL} \\
X_{27}\end{array}$ & $\begin{array}{l}0,29 \mathrm{TL} \\
1110\end{array}$ & 23100 \\
\hline \multirow[t]{2}{*}{$\begin{array}{l}\mathrm{U} 3 \\
0,12\end{array}$} & (S3) & $\begin{array}{l}0,18 \mathrm{TL} \\
X_{31}\end{array}$ & $\begin{array}{l}0,24 \mathrm{TL} \\
X_{32}\end{array}$ & $\begin{array}{l}0,007 \mathrm{TL} \\
8090\end{array}$ & $\begin{array}{l}0,26 \mathrm{TL} \\
1000\end{array}$ & $\begin{array}{l}0,35 \mathrm{TL} \\
X_{35}\end{array}$ & $\begin{array}{l}0,36 \mathrm{TL} \\
X_{36}\end{array}$ & $\begin{array}{l}0,14 \mathrm{TL} \\
1950\end{array}$ & $\begin{array}{l}0,42 \mathrm{TL} \\
X_{38}\end{array}$ & 11040 \\
\hline & İstem & 98850 & 21150 & 8090 & 18890 & 3500 & 3200 & 1950 & 1110 & $\begin{array}{l}156740 \\
156740\end{array}$ \\
\hline
\end{tabular}

Yukarıdaki tabloda oluşturulan yeni dağıtıma göre yapılan hesaplama sonucunda toplam maliyetin 5703.66 TL olduğu görülmüştür. 
C24=0,192-0,190=0,002

Yol Haritas1: C24=C14-C11+C21-C24

$=17890-98010+840-0=17050-98850+0-840$

TOPLAM MALIYET $=5703.66$

MODI Optimallik testinin 3. Aşaması Tablo 6'da gösterilmiştir.

Tablo 6. MODI Optimal Çözüm Yaklaşımı (3. Aşamanın sonu)

\begin{tabular}{|c|c|c|c|c|c|c|c|c|c|c|}
\hline & & $\begin{array}{l}\text { V1 } \\
0,008\end{array}$ & $\begin{array}{l}\mathrm{V} 2 \\
0,002\end{array}$ & $\begin{array}{l}\text { V3 } \\
-0,113\end{array}$ & $\begin{array}{l}\mathrm{V} 4 \\
0,14\end{array}$ & $\begin{array}{l}\text { V5 } \\
0,19\end{array}$ & $\begin{array}{l}\text { V6 } \\
0,20\end{array}$ & $\begin{array}{l}\mathrm{V} 7 \\
0,02\end{array}$ & $\begin{array}{l}\text { V8 } \\
0,24\end{array}$ & \\
\hline & & (D1) & (D2) & (D3) & (D4) & (D5) & (D6) & D7) & (D8) & Sunum \\
\hline $\begin{array}{l}\mathrm{U} 1 \\
0\end{array}$ & (S1) & $\begin{array}{l}0,008 \mathrm{TL} \\
98850\end{array}$ & $\begin{array}{l}0,06 \mathrm{TL} \\
X_{12}\end{array}$ & $\begin{array}{l}0,18 \mathrm{TL} \\
X_{13}\end{array}$ & $\begin{array}{l}0,14 \mathrm{TL} \\
17050\end{array}$ & $\begin{array}{l}0,19 \mathrm{TL} \\
3500\end{array}$ & $\begin{array}{l}0,20 \mathrm{TL} \\
3200\end{array}$ & $\begin{array}{l}0,32 \mathrm{TL} \\
X_{17}\end{array}$ & $\begin{array}{l}0,25 \mathrm{TL} \\
X_{18}\end{array}$ & 122600 \\
\hline $\begin{array}{l}\mathrm{U} 2 \\
0,05\end{array}$ & (S2) & $\begin{array}{l}0,06 \mathrm{TL} \\
X_{21}\end{array}$ & $\begin{array}{l}0,007 \mathrm{TL} \\
21150\end{array}$ & $\begin{array}{l}0,24 \mathrm{TL} \\
X_{23}\end{array}$ & $\begin{array}{l}0,19 \mathrm{TL} \\
840\end{array}$ & $\begin{array}{l}0,25 \mathrm{TL} \\
X_{25}\end{array}$ & $\begin{array}{l}0,26 \mathrm{TL} \\
X_{26}\end{array}$ & $\begin{array}{l}0,36 \mathrm{TL} \\
X_{27}\end{array}$ & $\begin{array}{l}0,29 \mathrm{TL} \\
1110\end{array}$ & 23100 \\
\hline \multirow[t]{2}{*}{$\begin{array}{l}\mathrm{U} 3 \\
0,12\end{array}$} & (S3) & $\begin{array}{l}0,18 \mathrm{TL} \\
X_{31}\end{array}$ & $\begin{array}{l}0,24 \mathrm{TL} \\
X_{32}\end{array}$ & $\begin{array}{l}0,007 \mathrm{TL} \\
8090\end{array}$ & $\begin{array}{l}0,26 \mathrm{TL} \\
1000\end{array}$ & $\begin{array}{l}0,35 \mathrm{TL} \\
X_{35}\end{array}$ & $\begin{array}{l}0,36 \mathrm{TL} \\
X_{36}\end{array}$ & $\begin{array}{l}0,14 \mathrm{TL} \\
1950\end{array}$ & $\begin{array}{l}0,42 \mathrm{TL} \\
X_{38}\end{array}$ & 11040 \\
\hline & İstem & 98850 & 21150 & 8090 & 18890 & 3500 & 3200 & 1950 & 1110 & $\begin{array}{l}156740 \\
156740\end{array}$ \\
\hline
\end{tabular}

TOPLAM MALIYET $=5701.98$

MODI optimallik testi tekrar uygulanan dağıtım planının optimallik şartını sağladığı görülmektedir. Meşrubat firmasının mevcut aylık dağıtım maliyetinin 6396.58 TL olmasına rağmen, firmanın ulaştırma modeli ile oluşturulan yeni dağıtım planını uygulaması durumunda toplam dağıtım maliyetinin $5701.98 \mathrm{TL}$ olacağ ve \% 10.86 oranında bir tasarruf sağlayacağı tespit edilmiştir.

\section{Sonuç}

Günümüzde faaliyet gösteren işletmelerin artan rekabet ortamında karlılıklarını muhafaza etmek ve sürdürülebilirliklerini sağlamak maksadıyla çeşitli kararlar almaları, ürün veya hizmetler için çeşitli iyileştirmeler yapmaları bir zorunluluk haline gelmektedir. Ayrıca talep edilen ürün veya hizmetlerin hızlı bir biçimde ve en iyi kalitede karşılanması iş dünyasının temel prensibidir. Bundan dolayı işletmelerin sektörde bulunan rakipleriyle rekabet edebilmesi için maliyetlerin azaltması ve en aza indirmesi kaçınılmaz bir zorunluluktur.

Toplam maliyetler içinde en önemli kalemlerinden biri olan dağıtım maliyetlerinin minimum düzeye indirilme çabaları işletmelerin bulundukları sektörlerdeki rekabet ve sürdürülebilirliği açısından hayati öneme sahiptir. Dağıtımı maliyetlerinin azaltılması için geliştirilen modellerin en başında ulaştırma modelleri gelmektedir. Ayrıca ulaştırma modelleri, teorik ve ekonomik bakımdan çokça çalışmalar yapılan ve üzerinde durulan konuların başında gelmektedir. 
Çalışmanın ilk üç bölümünde ulaştırma modeline dair çeşitli teorik bilgiler verilmiştir. Uyguma bölümünde, Bingöl İlinde faaliyet gösteren bir meşrubat firmasının dağıtım planlaması için ulaştırma modeli uygulanmak suretiyle yeni bir çözüm sunulmuştur.

Meşrubat firmasından elde edilen dağıtım verileri, Vogel (VAM) Başlangıç Yöntemi ile çözülmeye çalışılmıştır. Başlangıç çözüm yöntemlerinden biri olan Vogel (VAM) Başlangıç Yöntemi’nin kullanılmasının nedeni optimal çözüme en yakın sonucu vermesidir. Başlangıç çözümün optimal olup olmadığını test etmek için ise MODI Optimal Çözüm Yaklaşımı uygulanmıştır.

Ulaştırma modeli kullanılarak elde edilen meşrubat firmasının aylık toplam dağıtım maliyeti ile mevcut aylık toplam dağıtım maliyeti arasında \% 10.86 oranında tasarruf yapılabilecek bir dağıtım planı oluşturulmuştur. Çalışmanın sonucuna göre, işletmelerin ulaştırma modelleri yardımıyla taşıma maliyetlerini önemli ölçüde azaltabilecekleri, ekonomik ve rekabet güç bakımından sektördeki rakiplere göre avantajlı duruma gelebilecekleri gösterilmiştir.

\section{Kaynakça}

Çatı, K., \& Baydaş, A. (Edt.) (2008). Hizmet Pazarlaması ve Hizmet Kalitesi. Ankara: Asil Yayın Dağıtım.

Doğan, İ. (2005). Yöneylem Araştırması Teknikleri ve Işsletme Uygulamaları. İstanbul: Bilim Teknik Yayınevi.

Düzakın, E. (2005). İşletme Yöneticileri İçin Excel İle Sayısal Karar Verme teknikleri. İstanbul: Kare Yayınları.

Ertuğrul, İ., \& Tuş Işık, A. (2008). Bir Gıda İşletmesinde Ulaştırma Modeli İle Yeni Bir Dağıtım Planı Geliştirme. KMU IIIBF Dergisi , 10 (14).

Esin, A. (1988). Yöneylem Araştırmalarında Yararlanılan Karar Yöntemleri. Ankara.

Görkey, S. (2009). Ulaştırma Modelleri ve Bir Uygulama. Marmara Üniversitesi SBE Yüksek Lisans Tezi . İstanbul.

Hallaç, O. (1978). Kantitatif Karar Verme Teknikleri (Yöneylem Araştırması). İstanbul: Arpaz Matbaacilik.

Karaoğlan, İ., \& Altıparmak, F. (2005). Konkav Maliyetli Ulaştırma Problemi İçin Genetik Algoritma Tabanlı Sezgisel Bir Yaklaşım. Gazi Üniversitesi Mühendislik Mimarlık Fakültesi Dergisi , 20 (4), 443-454.

Özkan, Z. (2012). Ulaştırma Modelleri Ve Çelik Kapı Sektöründe Bir Uygulama.

Öztürk, A. (2004). Yöneylem Araştırması. Bursa: Ekin Kitap Evi.

Patır, S. (2009). Dinamik Programlama ve Bir Ecza Deposunun Şehir İçi İlaç Dağıtımına Alternatifli Bir Çözüm Önerisi. Atatürk Üniversitesi İktisadi ve İ́dari Bilimler Dergisi , 23 (2), 63-79.

Sarıaslan, H. (1986). Kaynak Dă̆glımda Doğrusal Proglama. Ankara: Ankara Üniversitesi, S.B.F. Yay.

Serper, Ö., \& Gürsakal, N. (1982). Doğrusal Programlama. Bursa: B.İ.T.İ.A. İşletme Fak. Yayını No:15.

Tekin, M. (2008). Sayısal Yöntemler. Konya. 
Tekin, M. (2004). Sayısal Yöntemler: Bilgisayar Çözümlü Araştırmalar. Konya.

Timor, M. (2001). Yöneylem Arastırması ve İşletmecilik Uygulamaları. İstanbul: İstanbul Üni. Basımevi Müdürlüğü.

Yang, L., \& Liu, L. (2007). Fuzzy fixed charge solid transportation problem and algorithm. Applied Soft Computing , 7, 879-889. 